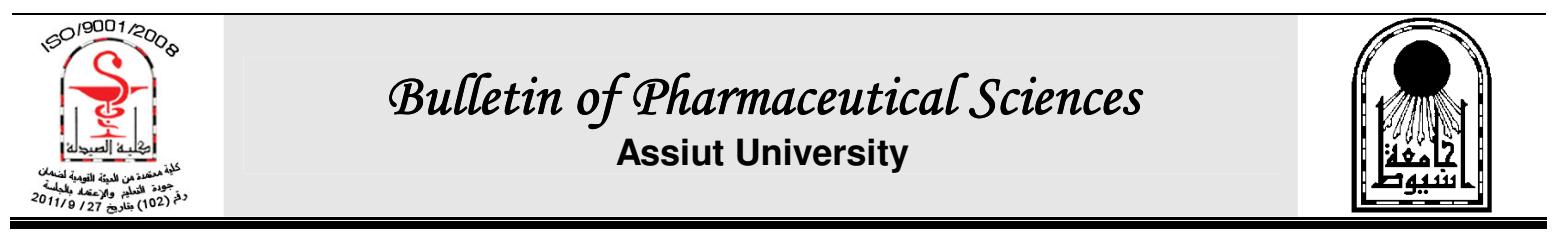

\title{
PREVALENCE OF NOSOCOMIAL INFECTIONS CAUSED BY PSEUDOMONAS AERGINOSA IN ASSIUT UNIVERSITY HOSPITAL
}

Ismail Seddik Soliman, Ehsan Abd El-Sabor Hassan, Noha Abd El-Haleem Afifi, Sherin Ahmed Abd El-Rahman and Ayat Mostafa Kamel

Department of Medical Microbiology and Immunology, Faculty of Medicine, Assiut University, Assiut, Egypt

Pseudomonas (Ps.) aeruginosa is one of the most common pathogens causing nosocomial infections. This pathogen causes several infections including urinary tract infection (UTI), wound infection, pneumonia, bacteremia,...etc. Immunocompromised patients and patients in intensive care unit are at high risk of acquisition of infection, in addition multidrug resistant Ps. aeruginosa isolates had been characterized.

This study was planned to determine the frequency of Ps. aeruginosa in nosocomially infected patients in Assiut university hospital and to type isolated strains.

In this study, 677 samples collected from 366 nosocomially infected patients admitted to different hospital wards at Assiut University Hospitals, including chest, trauma, neurology, internal medicine, post operative and pediatric ICUs, trauma and hematology units. Identification of bacterial strains was done by cultural and biochemical tests. Biotyping analysis for isolated strains was done using API 20NE.

In our study, a total of 30 (8.2\%) Ps. aeruginosa strains were isolated. Four API codes profile for Ps. aeruginosa isolates were identified, the isolate with API code profile 1154575 was more frequent distributed in Assiut University Hospital.

\section{INTRODUCTION}

Ps. aeruginosa is Gram-negative, nonsporing rods, motile, oxidase positive while indole, vogeus proskeur and nitrate negative ${ }^{1}$. About $10-15 \%$ of Ps. aeruginosa strains produce pigment only when grown on pigmentenhancing media ${ }^{2}$.

Ps. aeruginosa is an important opportunistic pathogen which plays an important role in hospital intensive care units. The presence of multiple intrinsic and acquired mechanisms of resistance to a wide variety of antibiotics in Pseudomonas aeruginosa allows spread of pathogen and makes pathogen control is difficult ${ }^{3 \& 4}$.

It has been reported that $P$ s. aeruginosa is the second most common cause of nosocomial pneumonia, health care-associated pneumonia, and ventilator-associated pneumonia. Ps.

Received in 9/3/2016 \& Accepted in 5/3/2017

*Corresponding author: Ayat Mostafa Kamal, E-mail: ayatmk@aun.edu.eg aeruginosa was accountable for $30 \%$ of pneumonias, $19 \%$ of urinary tract infections, and $10 \%$ of bloodstream infections ${ }^{4-6}$.

A study conducted by Hassan et al. ${ }^{7}$ at Assiut University Hospitals, reported that Ps. aeruginosa accounts for $17.73 \%$ of isolated uropathogens. In another study at Cairo University Hospitals, Wassef et al. ${ }^{8}$ reported that the highest isolation of Ps. aeruginosa were from lower respiratory tract infections (44.2\%), followed by surgical site infections (SSIs), burns \&skin infections (37.5\%) and urinary tract infections $(23.2 \%)$.

There are several typing systems for isolated Ps. aeruginosa strains; biotyping", antibiogram $^{10}$, pyocin typing ${ }^{11}$, serotyping ${ }^{12}$, phage typing ${ }^{13}$ and molecular typing ${ }^{14}$. 


\section{MATERIAL AND METHODS}

\section{Study population}

This study was conducted on 366 nosocomially infected patients admitted to different hospital wards at Assiut University Hospitals, including chest, trauma, neurology, internal medicine, post-operative and pediatric ICUs, trauma and hematology units during a period of 12 months from May 2014 to May 2015. Six hundred seventy seven specimens were collected according to the site of infection: endotracheal tubes $(n=218)$, sputum samples $(n=171)$, blood $(n=167)$, urine samples $(n=78)$, wound swabs $(n=23)$, and throat swabs $(n=20)$. There was more than one sample collected from one patient.

\section{Bacteriological examination}

All samples were inoculated on blood agar, MacConkey's agar, Mannitol salt agar and Cetrimide agar. Suspected colonies were subcultured on Pseudomonas agar (for pyocyanin).

Identification and confirmation of isolates was done by Gram stain, colony morphology, oxidase test, Triple Sugar Iron test (TSI), Simmon's Citrate, Christensen's urea, catalase test and ability to grow at $42^{\circ} \mathrm{C}$.

\section{Biotyping of isolated Ps. aeruginosa strains}

Typing of Ps. aeruginosa strains $(\mathrm{n}=30)$ was done using API 20NE kit (BioMerieux, Marcy L Etoile; France).

\section{RESULTS AND DISCUSSION}

\section{Results}

Ps. aeruginosa was identified as Gramnegative, non-sporing rods, oxidase +ve, reduce nitrate to nitrite, not ferment sugars and citrate positive, urease $-\mathrm{ve}$, catalase +ve and can grow at $42^{\circ} \mathrm{C}$.

Ps. aeruginosa grew on blood agar as mucoid colonies, grew on MacConkey's agar as non-lactose fermenting colonies (NLF), grew on Cetrimide agar and grew on Pseudomonas agar (for pyocyanin) showing greenish blue colonies as shown in figures $1 \mathrm{a} \& 1 \mathrm{~b}$.

In this study, 162/366 (44.26\%) females and 204/366 (55.74\%) males were included. The age of patients ranged from two months to 82 years. One hundred sixty patients aged above 40 years (43.7\%), 120 patients aged 18-
40 years $(32.8 \%)$ and 86 patients were children ( $<18$ years) $(23.5 \%)$.

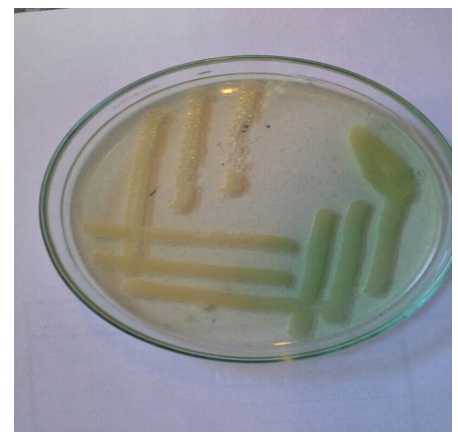

Fig. 1a: Colonies of Ps. aeruginosa on Cetrimide agar.

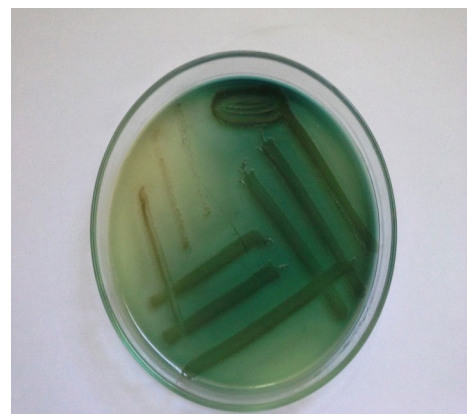

Fig. 1b: Greenish blue colonies of Ps. aeruginosa on Pseudomonas agar (for pyocyanin)

One thousand and one hundred forty eight pathogens (1148) were isolated. Of these, 515 $(44.86 \%)$ were Enterobacteriaceae, 317 (27.6\%) were Staphylococci spp., 120 (10.45\%) were Candida spp., 30 (2.63\%) were Ps. aeruginosa, and 166 (14.46\%) were other non-Enterobacteriaceae which include Acinetobacter spp., Stenotrophomonas spp., and other Pseudomonas spp. (Fig. 2).

Ps. aeruginosa represented $2.63 \%$ (30/1148) from total isolates, 4.43\% (30/677) from total number of samples, and $8.2 \%$ (30/366) from number of nosocomially infected patients. The frequency of Ps. aeruginosa from different samples is summarized in table 1.

Ps. aeruginosa isolates were mostly isolated from neurology ICU by $33.33 \%$ (10/30) followed by chest ICU representing $26.67 \%$ (8/30), trauma ICU and internal medicine ICU by $10 \%$ (3/30) each, hematology unit and pediatric ICU by $6.68 \%(2 / 30)$ each, and then post-operative ICU and trauma unit by $3.33 \%$ (1/30) (Fig. 3). 


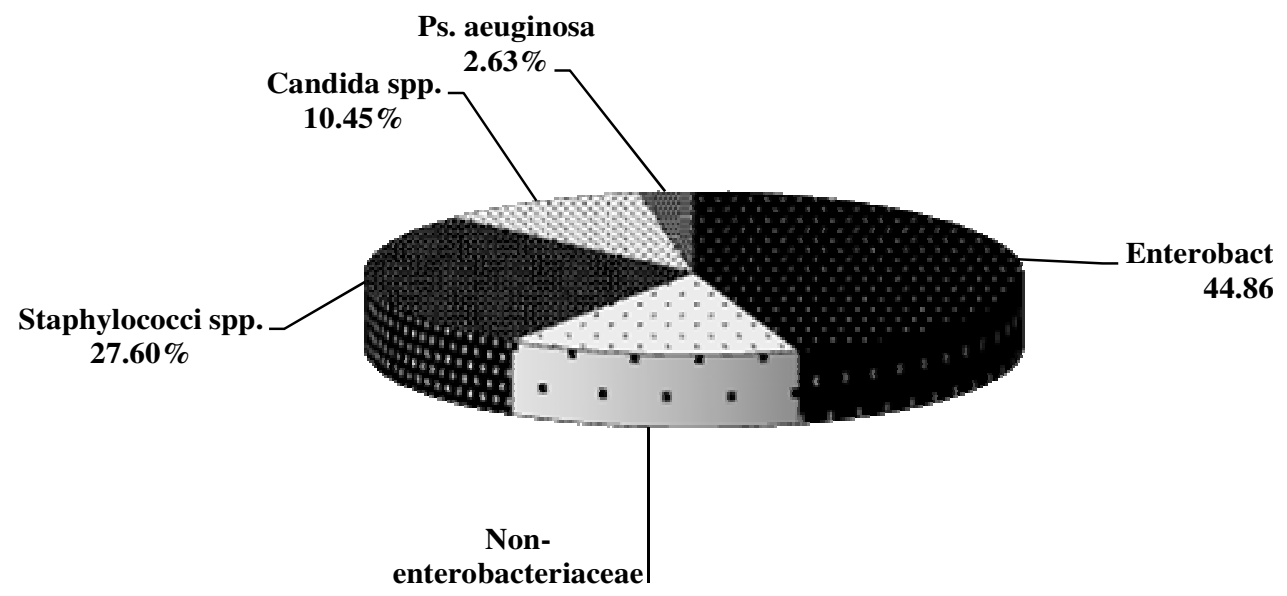

Fig. 2: Types of pathogens identified out of total 1148 isolates from nosocomially infected patients.

Table 1: Frequency of $P$ s. aeruginosa in 677 samples from nosocomially infected patients.

\begin{tabular}{|c|l|}
\hline No. Of Ps. aeruginosa isolates & \multicolumn{1}{|c|}{ Samples } \\
\hline 15 & Endotracheal aspirates $(\mathrm{n}=218)$ \\
\hline 8 & Sputum samples $(\mathrm{n}=171)$ \\
\hline 1 & Blood culture $(\mathrm{n}=167)$ \\
\hline 3 & Wound swabs $(\mathrm{n}=23)$ \\
\hline 2 & Urine samples $(\mathrm{n}=78)$ \\
\hline 1 & Throat swabs $(\mathrm{n}=20)$ \\
\hline Total $(\mathrm{n}=30)$ & Total $=(677)$ \\
\hline
\end{tabular}

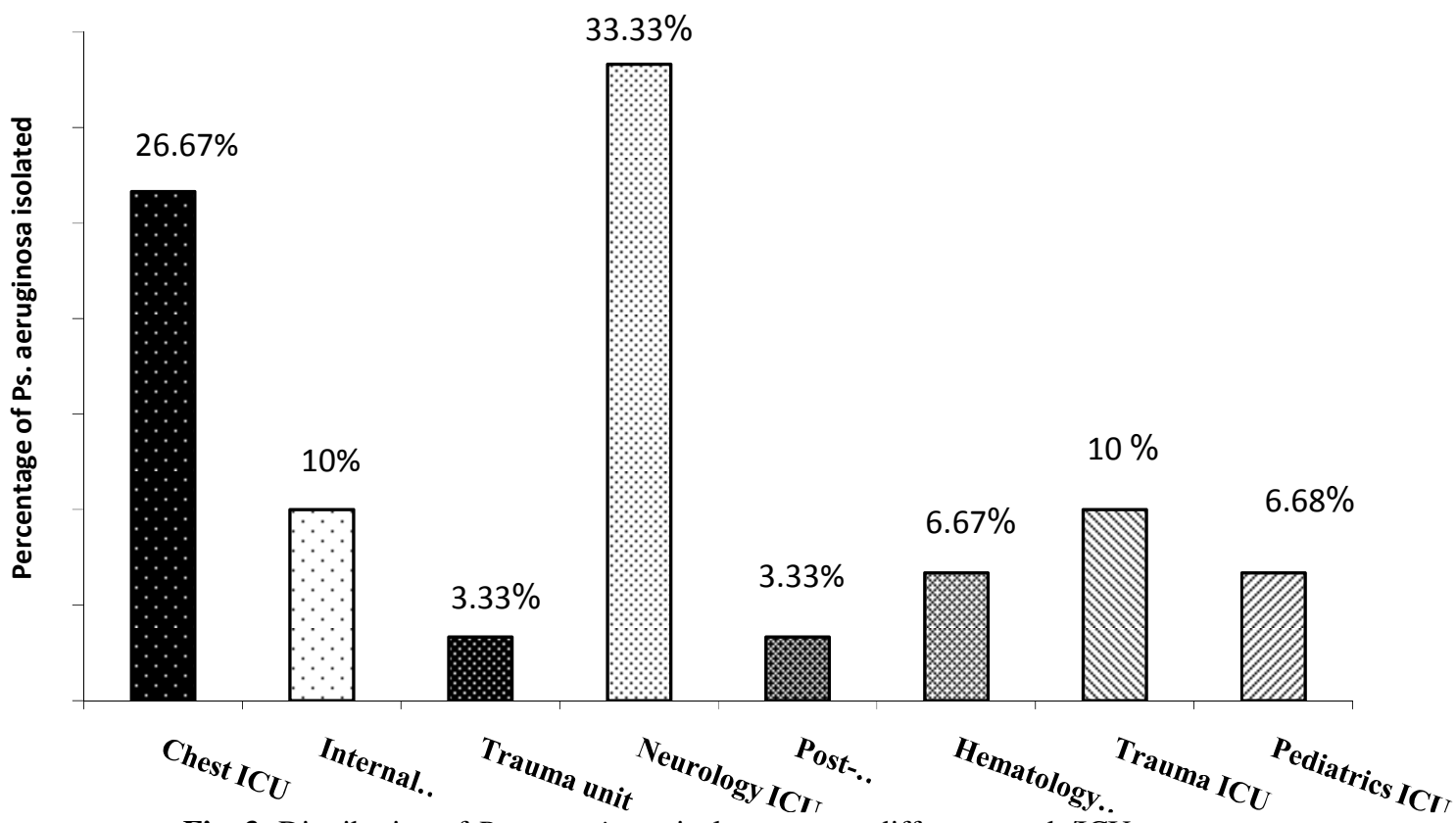

Fig. 3: Distribution of Ps. aeruginosa isolates among different wards/ICUs. 


\section{Results of API 20NE}

The API 20NE Index system was performed to identify 30 isolated strains of $P s$. aeruginosa.

The API 20 NE Index system identified 30 isolates of Ps. aeruginosa with four different analytic profile index numbers (nine strains with 1154575 code, eight strains with 0354575 code, eight strains with 0154575 code, and five strains with 0144575 code) as shown in table 2 and figure 4 .

Table 2: Biotyping of Ps. aeruginosa isolates with API 20 NE:

\begin{tabular}{|c|c|c|}
\hline Infection Site & $\begin{array}{l}\text { No. of } \\
\text { isolates }\end{array}$ & $\begin{array}{l}\text { API code } \\
\text { profile }\end{array}$ \\
\hline \multirow{3}{*}{$\begin{array}{l}\text { Chest ICU } \\
\qquad(\mathrm{n}=8)\end{array}$} & 4 & 1154575 \\
\hline & 2 & 0354575 \\
\hline & 2 & 0154575 \\
\hline \multirow{2}{*}{$\begin{array}{c}\text { Trauma ICU } \\
(n=3)\end{array}$} & 2 & 0144575 \\
\hline & 1 & 1154575 \\
\hline \multirow{3}{*}{$\begin{array}{l}\text { Neurology ICU } \\
\quad(\mathrm{n}=10)\end{array}$} & 4 & 0354575 \\
\hline & 3 & 1154575 \\
\hline & 3 & 0154575 \\
\hline $\begin{array}{l}\text { Trauma unit } \\
(\mathrm{n}=1)\end{array}$ & 1 & 1154575 \\
\hline $\begin{array}{c}\text { Pediatrics ICU } \\
(\mathrm{n}=2)\end{array}$ & 2 & 0154575 \\
\hline $\begin{array}{l}\text { Internal medicine ICU } \\
(\mathrm{n}=3)\end{array}$ & 3 & 0144575 \\
\hline $\begin{array}{c}\text { Postoperative ICU } \\
(\mathrm{n}=1)\end{array}$ & 1 & 0154575 \\
\hline $\begin{array}{l}\text { Hematology unit } \\
(\mathrm{n}=2)\end{array}$ & 2 & 0354575 \\
\hline
\end{tabular}

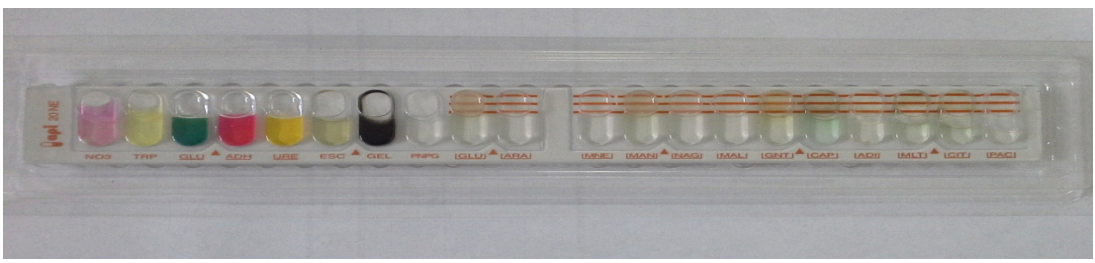

(A)Code 1154575

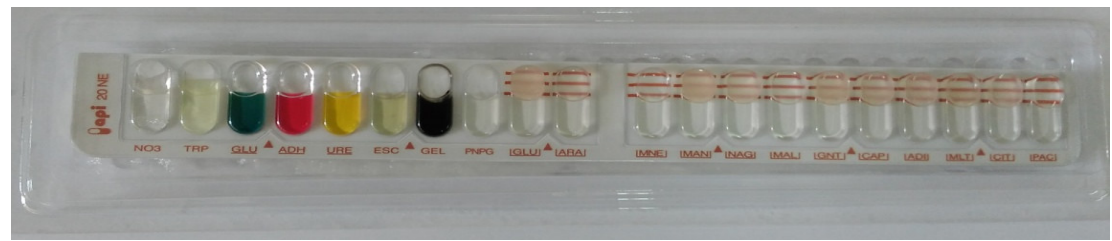

(B) Code 0154575

Fig. 4: Biotyping of Ps. aeruginosa isolate with API 20 NE 


\section{Discussion}

In our study, Ps. aeruginosa strains represented $4.43 \%$ from total number of samples in Assiut university hospital. Our results are comparable to previous results reported by Morrison and Wenzel ${ }^{15},(8.5 \%)$ and Nadeem et al. ${ }^{16},(10.1 \%)$. However, higher Ps. aeruginosa infection rate were reported by others; Mansour et al. ${ }^{17}$, reported the rate of Ps. aeruginosa isolation from patient samples in Egypt and Saudi Arabia, was $32.8 \%$ and $30.0 \%$ respectively, also Wassef et $a l^{8}{ }^{8}$, reported that the percentage of Ps. aeruginosa isolates in clinical samples was $20.7 \%$ and Gad et al. ${ }^{18}$ detected $18.2 \%$ of Ps. aeruginosa in different clinical samples.

In the current study, Ps. aeruginosa isolates represented $8.2 \% \quad(30 / 366)$ from number of nosocomially infected patients. Our results are similar to some extent to previous results reported by Abbas et al. ${ }^{19}$ (12.5\%). However, higher Ps. aeruginosa percentage (18.8\%) were reported by Mahmoud et al. ${ }^{20}$.

In the present study, Ps. aeruginosa was detected in $13.04 \%(3 / 23)$ of infected wounds. Similar findings (11-12\%) were reported by other groups Gad et al. ${ }^{18}$; Cayci et al. ${ }^{21}$. While, higher rates were reported by Mahmoud et al. ${ }^{20}$ who found Ps. aeruginosa in 5\% (3/54) of wound swab samples collected from El-Minia University Hospital,Egypt and Jamasbi and Proudfoot $^{12}$ who detected Ps. aeruginosa in $32.9 \%(55 / 167)$ of wound exudate samples were obtained from a Northwest Ohio hospital, USA.

In this work, Ps. aeruginosa isolates were recovered from $5.9 \%$ (23/389) of respiratory tract infection cases. These results agreed to some extent with Gad et al. ${ }^{18}$, who detected Ps. aeruginosa in $6 \%$ of samples collected from patients suffering from respiratory tract infections in El-Minia University Hospital, Egypt. However, these results were lower than the findings by Mahmoud et al. ${ }^{20}$ who detected Ps. aeruginosa in $14.8 \%$ (8/54) of sputum samples collected from patients suffering from respiratory tract infections over a 3-year study period in Menofia University Hospitals, Egypt and also Fatima et $a ._{.22}$ detected Ps. aeruginosa in $24 \%$ of sputum samples of lower respiratory tract infection patients admitted to different hospitals of Karachi, Pakistan over a 14 months period from January 2010 to March 2011.
In this study, Ps. aeruginosa were recovered from $2.6 \%(2 / 78)$ of urinary tract infection cases. These findings were less than the results published by Hassan et al. ${ }^{7}$, who detected Ps. aeruginosa in $8.6 \%(50 / 581)$ in samples collected from urinary tract infections patients at Urology Department in Assiut University Hospital, Egypt.

In the current study, Ps. aeruginosa was detected in $0.6 \%(1 / 167)$ of blood cultures (1/167). Our results were lower than those reported by Cayci et $a .^{21}$, who detected Ps. aeruginosa in $3.3 \%$ of samples.

The difference in prevalence rate in each unit and/or sample in our results than other previously reported results may be attributed to difference in patient population, underlying diseases, environments, study periods, and the number of investigated specimens.

Identification and biotyping of $P s$. aeruginosa was done by API 20NE. Four API codes profile for Ps. aeruginosa isolates were identified 1154575, 0154575, 0354575 and 0144575. Ps. aeruginosa with API code profile 1154575 was most frequent isolated, followed by strains with API code 0154575 and 0354575. While isolates characterized by API code 0144575 was less frequent distributed.

\section{Conclusion}

Ps. aeruginosa is a common cause of nosocomial infection in Assiut university hospitals. Ps. aeruginosa with API code profile 1154575 was mostly identified.

\section{REFERENCES}

1- J. W. Govan, "Pseudomonas", In: "Mackie \& McCarteny Practical Medical Microbiology", J. G. Collee, J. P. Duguid, A. G.Fraser, and B. P. Marmion (Eds.), $13^{\text {th }} \quad$ Ed., Edinburgh: Churchill Livingstone, Vol. 2, 1989, pp. 491-502.

2- J. W. Govan, "Pseudomonas and NonFermenters", In: "Medical Microbiology: A Guide to Microbial Infections: Pathogenesis, Immunity, Laboratory Diagnosis and Control", D. Greenwood, R. Slack, J. Peutherer, \& M. Barer (Eds.), $7^{\text {th }} \quad$ Ed., Churchill LivingstoneELSEVIER, 2007, pp. 293-299.

3- D. Landman, J. M. Quale, D. Mayorga, A. Adedeji, K. Vangala, J. Ravishankar, C. 
Flores and S. Brooks, "Citywide clonal outbreak of multiresistant Acinetobacter baumannii and Pseudomonas aeruginosa in Brooklyn, NY: The preantibiotic era has returned", Archives of Internal Medicine, 162, 1515-1520 (2002).

4- P. D. Lister, D. J. Wolter and N. D. Hanson, "Antibacterial-resistant Pseudomonas aeruginosa: Clinical impact and complex regulation of chromosomally encoded resistance mechanisms", Clinical Microbiology Reviews, 22, 582-610 (2009).

5- M. H. Kollef, A. Shorr, Y. P. Tabak, V. Gupta, L. Z. Liu and R. Johannes, "Epidemiology and outcomes of healthcare-associated pneumonia: Results from a large US database of culture-positive pneumonia", CHEST Journal, 128, 38543862 (2005).

6- R. A. Weinstein, R. Gaynes and J. R. Edwards, "Overview of nosocomial infections caused by gram-negative bacilli", Clinical Infectious Diseases, 41, 848-854 (2005).

7- I. A. E. S Hassan, S. S. Seif El-din, A. M. Nafei and M. A. Abd El-Hafiz, "Comparative studies of different efflux pump inhibitors effect on pseudomonas aeruginosa resistant to fluoroquinolone", New Egyptian Journal of Microbiology, 32 (2012).

8- M. Wassef, H. El Mahallawy, M. M. Zafer, G. Doaa and R. abdel hamid, "Lab based surveillance of multidrug resistant pseudomonas aeruginosa in Cairo University Hospitals, Egypt", Journal of Microbiology \& Experimentation, 2, 5 (2015).

9- A. Freitas and A. L. Barth, "Typing of pseudomonas aeruginosa from hospitalized patients: A comparison of susceptibility and biochemical profiles with genotype", Brazilian Journal of Medical and Biological Research, 37, 7782 (2004).

10- Clinical and Laboratory Standards Institute (CLSI), "Performance Standards for Antimicrobial Susceptibility Testing, Informational Supplement M100-S18", $18^{\text {th }}$ Ed., CLSI, Wayne, PA, (2008).

11- J. Fyfe, G. Harris and J. Govan, "Revised pyocin typing method for Pseudomonas aeruginosa", Journal of Clinical Microbiology, 20, 47-50 (1984).

12- R. J. Jamasbi and E. M. Proudfoot, "Phenotypic and genotypic characteristics of clinical isolates of pseudomonas aeruginosa: Rate of occurrence and distribution of different serotypes, antimicrobial susceptibility profiles, and molecular typing", Lab Medicine, 39, 155-161 (2008).

13- B. Ojeniyi, C. Wolz, G. Döring, J. Lam, V. Rosdahl and N. Hoiby, "Typing of polyagglutinable Pseudomonas aeruginosa isolates from cystic fibrosis patients", APMIS, 98, 423-431 (1990).

14- T. J. Kidd, K. Grimwood, K. A. Ramsay, P. B. Rainey and S. C. Bell, "Comparison of three molecular techniques for typing Pseudomonas aeruginosa isolates in sputum samples from patients with cystic fibrosis", Journal of Clinical Microbiology, 49, 263-268 (2011).

15- A. J. Morrison and R. P. Wenzel, "Epidemiology of infections due to Pseudomonas aeruginosa", Review of Infectious Diseases, 6, S627-S642 (1994).

16- S. Nadeem, S. Qasmi, F. Afaque, M. Saleem and S. Hakim, "Comparison of the in vitro susceptibility of Clinical isolates of Pseudomonas aeruginosa in a local hospital setting in Karachi, Pakistan", British Journal of Medical Practitioners, 2, 35-39 (2009).

17- S. Mansour, O. Eldaly, A. F. Jiman, M. Mohamed and E. Ibrahim, "Epidemiological Characterization of $P$. aeruginosa Isolates of Intensive Care Units in Egypt and Saudi Arabia", (2013).

18- G. F. Gad, R. A. El-Domany, S. Zaki and H. M. Ashour, "Characterization of Pseudomonas aeruginosa isolated from clinical and environmental samples in Minia, Egypt: Prevalence, antibiogram and resistance mechanisms", Journal of Antimicrobial Chemotherapy, 60, 10101017 (2007).

19- S. H. Abbas, M. Naeem, M. Adil, S. M. Naz, A. Khan and M. U. Khan, "Sensitivity patterns of Pseudomonas aeruginosa isolates obtained from clinical specimens in Peshawar", Journal of Ayub 
Medical College Abbottabad, 27, 329-332 (2015).

20- A. B. Mahmoud, W. A. Zahran, G. R Hindawi, A. Z. Labib and R. Galal, "Prevalence of multidrug-resistant Pseudomonas aeruginosa in patients with nosocomial infections at a university hospital in Egypt, with special reference to typing methods", Journal of Virology \& Microbiology, 2013, 10-13 (2013).

21- Y. T. Cayci, A. Coban and M. Gunaydin, "Investigation of plasmid-mediated quinolone resistance in Pseudomonas aeruginosa clinical isolates", Indian Journal of Medical Microbiology, 32, 285 (2014).
22- A. Fatima, S. Nagvi and S. Khalig, "Antimicrobial susceptibility pattern of clinical isolates of Pseudomonas aeruginosa isolated from patients of lower respiratory tract infections", Springerplus, 1, 70 (2012). 


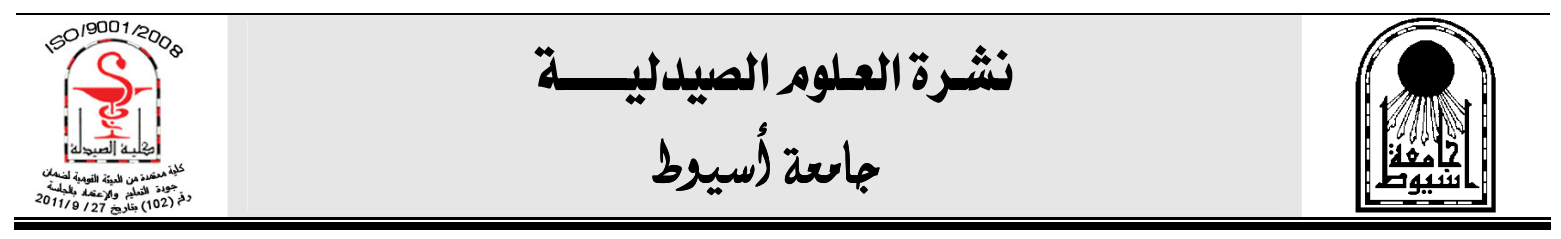

تحديد وتصنيف السودومونس ايرجينوز ابين مرضى العدوى المكتسبه للمستثفيات

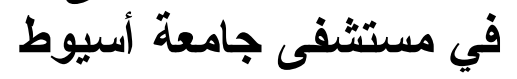

اسماعيل صديق سليمان - احسان عبد الصبور حسن - نها عبد الحليم عفيفي شيرين عبد الرحمن - آيات مصطفي كامل قسم الميكروبيولوجيا الطبيه والمناعه ، كليه الطب ، جائ جامعه اسيوط ، اسيوط ، مصر كري

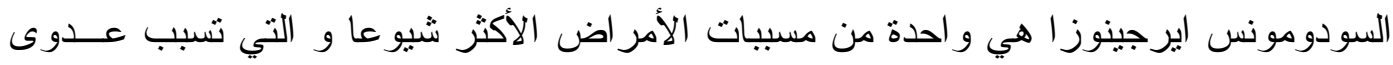

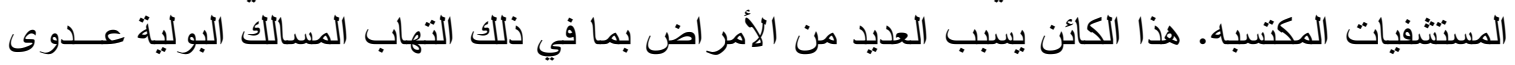

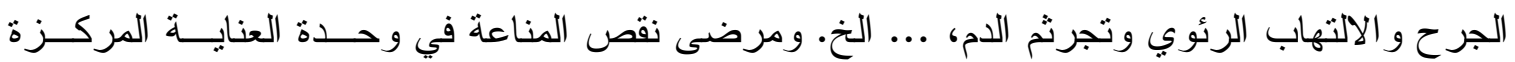

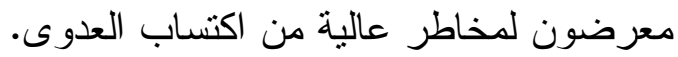

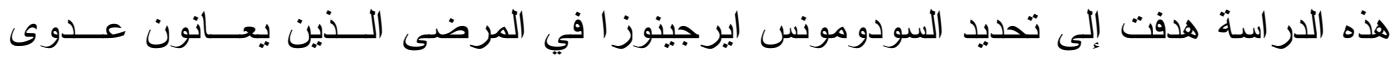

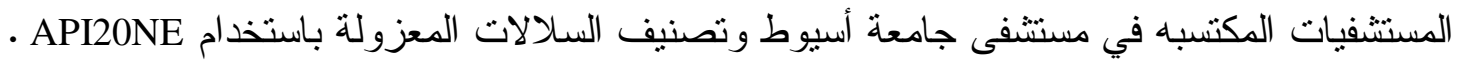
هذه الدر اسة شملت TVV

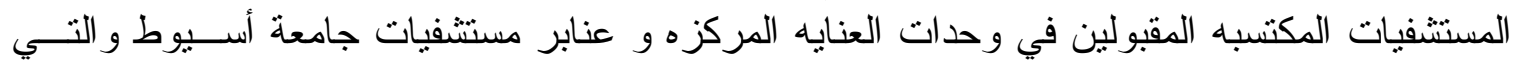

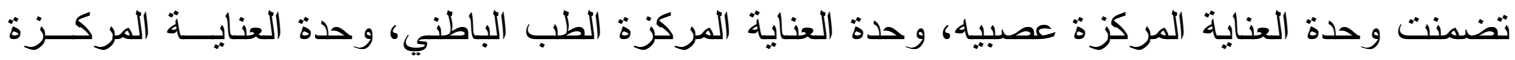

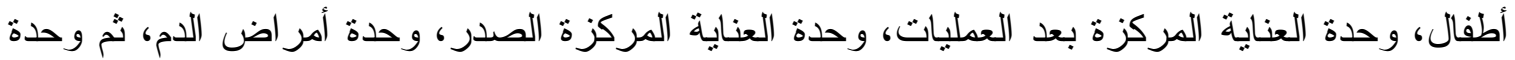

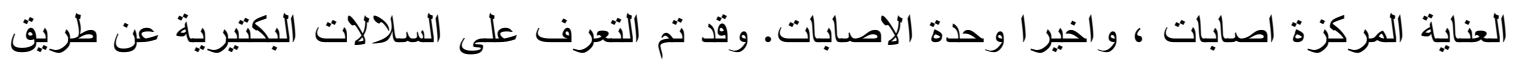

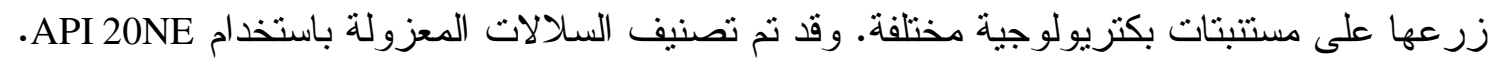

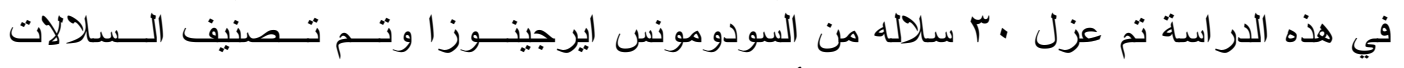

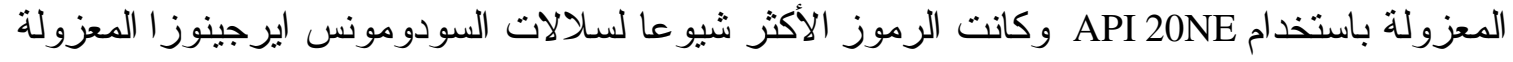

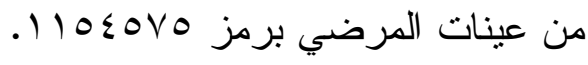

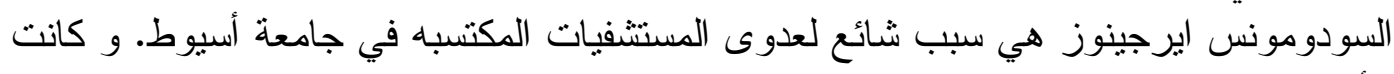

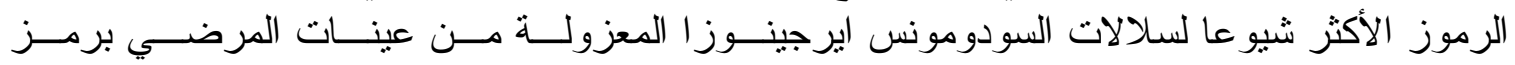

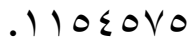

